\title{
Microbial Transformations of Uranium Complexed with Organic and Inorganic Ligands
}

\author{
Arokiasamy J. Francis \\ Environmental Sciences Department, Brookhaven National Laboratory, Upton, \\ New York, USA
}

\begin{abstract}
Biotransformation of various chemical forms of uranium present in wastes, contaminated soils and materials by microorganisms under different process conditions such as aerobic and anaerobic (denitrifying, iron-reducing, fermentative, and sulfate-reducing) conditions will affect the solubility, bioavailability, and mobility of uranium in the natural environment. Fundamental understanding of the mechanisms of microbial transformations of uranium under a variety of environmental conditions will be useful in developing appropriate remediation and waste management strategies as well as predicting the microbial impacts on the long-term stewardship of contaminated sites.
\end{abstract}

\section{Introduction}

Uranium exists in several oxidation states U(III), U(IV), U(V), and U(VI), of which $\mathrm{U}(\mathrm{IV})$ and $\mathrm{U}(\mathrm{VI})$ are the predominant ones in the environment. Uranium may be present in wastes and contaminated soils, and materials as elemental, oxide, coprecipitates, ionic, inorganic-, and organic-complexes, and naturally occurring minerals depending on the process and waste stream. Microbial activity could affect the chemical nature of the uranium by altering the speciation, soubility and sorption properties and thus could increase or decrease the mobility of uranium. Among the radionuclides, biotransformation of uranium has been extensively studied (Francis 1998). In this paper, biotransformation of several chemical forms of uranium under various microbial process conditions such as aerobic, denitrifying, iron-reducing, fermentative, and sulfate-reducing conditions are examined. 


\section{Microbial mobilization and immobilization of uranium}

Under appropriate conditions, dissolution or immobilization of uranium is brought about by direct enzymatic or indirect non-enzymatic actions of microorganisms. Both aerobic and anaerobic microorganisms are involved in the mobilization and immobilization of various chemical forms of uranium. Dissolution of uranium by autotrophic sulfur- and iron-oxidizing bacteria due to oxidation of inorganic compounds and by heterotorphic bacteria and by fungi due to production of organic acids and chelating agents such as siderophores has been reported.

Immobilization of $U$ is brought about by bioreduction and bioprecipitation reactions. Uranium is reduced by a wide variety of facultative and strict anaerobic bacteria under anoxic conditions in the presence of suitable electron donors.

$$
\left.\mathrm{U}(\mathrm{VI})_{\mathrm{aq}} \frac{\text { dissimilatory metal reducers }}{\text { fermenters, sulfatereducers }}\right\rangle \mathrm{U}(\mathrm{IV})_{\mathrm{s}}
$$

Consequently, the potential exists for the use of anaerobic bacteria to concentrate, contain and stabilize $U$ in contaminated groundwaters and in waste with concurrent reduction in waste volume. Reactive barrier technology is based on the activities of these anaerobic bacteria. However, the long-term stability of bacterially immobilized $U$ in the natural environment is poorly understood.

Biosorption and bioaccumulation of uranium has been observed in a wide range of microorganism. It is still one of the intensely investigated areas of research because of the potential use of biomass to remove $U$ from waste streams. Extracellular and intracellular association of $U$ with bacteria was observed but the extent of its accumulation differs greatly with the species of bacteria. Uranium forms complexes with the carboxylate, phosphate, amino, and hydroxyl functional groups present on the cell surface; and intracellularly, by binding to anionic sites or precipitating as dense deposits. Extended X-ray absorption fine structure (EXAFS) analysis of the association of $U$ with halophilic and non-halophilic bacterial cells showed that it was associated predominantly with phosphate as uranyl hydrogen phosphate and as hydroxophosphato or polyphosphate complexes as well as with other ligands such as carboxyl group. These and other studies show that cellular phosphates, including the polyphosphates, bind significant amounts of uranium (Panak et al, 1999, 2000; Sakaguchi, 1996; Francis et al manuscript submitted).

Uranium associated with the bacteria is not very stable, as it was removed completely by $\mathrm{Na}_{2} \mathrm{HCO}_{3}$ from Halomonas sp, from an Arthrobacter sp by 0.1 sodium hydrogen carbonate, 0.1M EDTA, and $\mathrm{Na}_{2} \mathrm{CO}_{3}$, and from Bacillus strains by EDTA (Panak et al, 1999; Sakaguchi, 1996; Francis et al manuscript submitted). 


\section{Biotransformations of uranium-organic and -inorganic complexes}

Although a wide variety of microorganisms are present in uranium mining wastes and in natural radioactive mineral deposits, the extent to which they regulate the mobility of uranium complexed with organic and inorganic ligands has not beenfully evaluated. Further, there is a paucity of information on the biotransformation of uranium complexed with naturally occurring organic ligands. Biotransformation of radionuclide-complexes may result in precipitation of the released ion as water-insoluble hydroxides, oxides or salts. Such transformations may result in the retardation of uranium migration. Current understanding of the biotransformation of uranium-complexed with organic and -inorganic ligands by aerobic and anaerobic (denitrifying, iron-reducing, fermentative, sulfate-reducing) bacteria is summarized below.

\section{Biotransformation under aerobic conditions}

Binary uranyl-citrate complex. Citric acid, a naturally occurring compound, is a multidentate ligand, which forms stable complexes with various metal ions. It forms different types of complexes with transition metals and actinides including formation of a bidentate, tridentate, binuclear, or polynuclear complex species. Biodegradation of metal citrate complexes is dependent upon the type of complex formed between the metal and citric acid; bidentate complexes are readily biodegraded whereas the tridentate complexes are recalcitrant (Francis et al 1992). Pseudomonas fluorescens metabolized the bidentate complexes whereas complexes involving the hydroxyl group of citric acid, and the binuclear U-citrate complex are not (Francis et al 1992). The presence of the free hydroxyl group of citric acid is the key determinant in effecting biodegradation of the metal complex. The lack of degradation was not due to their toxicity but was limited by the transport and/or metabolism of the complex by the bacteria. No relationship was observed between biodegradability and stability of the complexes.

Adding excess citric acid to equimolar $(0.52 \mathrm{mM})$ uranyl citrate resulted in the metabolism of the excess citric acid; the uranyl citrate complex was not toxic to the bacterium. In the presence of 1-, 2-, and 3-fold excess citric acid, the citric acid remaining in each complex after biodegradation was $0.75,0.80$, and 0.83 $\mathrm{mM}$, respectively. The final stoichiometry of U-citric acid in all three treatments was approximately $2: 3$, indicating the formation of 2:3 $\mathrm{U}$-citric acid complex.

Ternary Iron- and uranium-citrate complexes. Citric acid forms ternary mixedmetal complexes with various metal ions involving the hydroxyl and carboxyl groups of citric acid. The presence of 1:1:2 Fe:U:citric acid in solution was confirmed by potentiometric titration, UV-vis spectrophotometry, gel-filtration chromatography, and extended X-ray absorption fine structure (EXAFS) analysis (Dodge and Francis, 1997). Comparison of the EXAFS spectra show the 1:1:2 Fe:U:citric acid complex has structural characteristics similar to the 1:1 U:citric acid complex. Biotransformation studies of Fe-U-citrate complex by P. fluores- 
cens showed that the ternary 1:1:2 Fe:U:citric acid complex was recalcitrant. When a one-fold excess citric acid was added to this complex, the excess citric acid was completely degraded with no change in the stoichiometry of the complex. However, with two-fold excess citric acid, a 1:1:1 Fe:U:citric acid complex remained in solution after the excess citric acid was biodegraded. These results suggest that similar to the U-citrate complex, the Fe-U-citrate complex is recalcitrant to biodegradation (Dodge and Francis, 1997). The persistence of mixedmetal-citrate complexes in wastes and contaminated environments may result in the mobilization of uranium.

\section{Biotransformation under Denitrifying Conditions}

Metabolism of Uranyl-citrate Complex. Citrate metabolism by Pseudomonas fluorescens under denitrifying conditions was facilitated by the enzyme aconitase as in aerobic metabolism. Biodegradation of the various metal-citrate complexes by $P$. fluorescens under denitrifying conditions was similar to that observed aerobically, but the rates were much lower. The bacterium completely degraded bidentate complexes, whereas the tridentate complexes, and the binuclear U-citrate complex, were not metabolized by the bacterium (Joshi-Tope and Francis, unpublished results).

Biotransformation of uranyl-organic and -inorganic complexes. Biotransformations of uranyl nitrate, uranyl-citrate, uranyl-ethylenediaminetetraacetate (EDTA), and uranyl carbonate by a halophilic bacterium, Halomonas sp., isolated from the Waste Isolation Pilot Plant (WIPP) repository site was investigated under denitrifying conditions (Francis et al 2000).

Addition of uranyl nitrate, uranyl-citrate, or uranyl-EDTA to the brine bacterial growth medium containing $4 \mathrm{M} \mathrm{NaCl}$ resulted in the precipitation of uranium as a uranyl hydroxophosphato species $\left[\mathrm{K}\left(\mathrm{UO}_{2}\right)_{5}\left(\mathrm{PO}_{4}\right)_{3}(\mathrm{OH})_{2} \cdot \mathrm{nH}_{2} \mathrm{O}\right]$. Dissolution of the uranium precipitate was concomitant with the growth of the bacterium under denitrifying conditions (Figures 1-3).

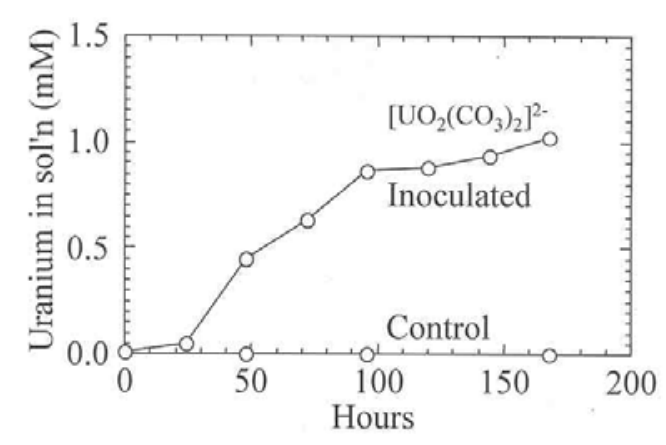

Fig. 1. Addition of uranyl nitrate to bacterial growth medium resulted in the precipitation of $U$ as uranyl phosphate. Growth of Halomonas sp. resulted in the solubilization of $\mathrm{U}$ as uranyl dicarbonate. 

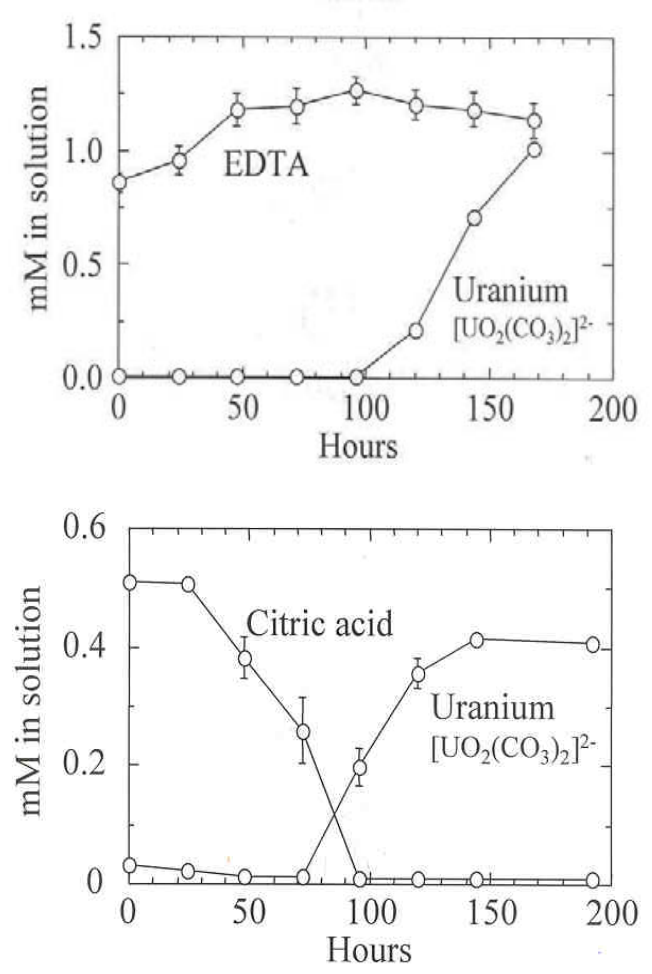

Fig. 2. Addition of uranylEDTA to bacterial growth medium resulted in the precipitation of $\mathrm{U}$ as uranyl phosphate. Halomonas sp. solubilized $U$ as uranyl dicarbonate. EDTA remained in solution and was not metabolized by the bacterium.

Fig. 3. Addition of uranylcitrate to bacterial growth medium resulted in the precipitation of $U$ as uranyl phosphate. Growth of Halomonas sp. resulted in the dissolution of $\mathrm{U}$ as uranyl dicarbonate. Citric acid was metabolized by the bacterium

The bacterium completely metabolized the citrate released from uranyl-citrate complex, but not the EDTA released from the U-EDTA complex. The UV-vis spectra of the culture medium during growth revealed the formation of a uranyl dicarbonate complex $\left[\mathrm{UO}_{2}\left(\mathrm{CO}_{3}\right)_{2}\right]^{2-}$ due to $\mathrm{CO}_{2}$ production from the metabolism of the carbon source. There was no change in the speciation of added uranyl carbonate. These results show that uranium phosphate is readily solubilized by bacterial action with formation of mobile to uranyl carbonate species.

Addition of uranyl nitrate, uranyl-citrate, or uranyl-EDTA to the brine bacterial growth medium containing $4 \mathrm{M} \mathrm{NaCl}$ resulted in the precipitation of uranium as a uranyl hydroxophosphato species $\left[\mathrm{K}\left(\mathrm{UO}_{2}\right)_{5}\left(\mathrm{PO}_{4}\right)_{3}(\mathrm{OH})_{2} \cdot \mathrm{nH}_{2} \mathrm{O}\right]$. Dissolution of the uranium precipitate was concomitant with the growth of the bacterium under denitrifying conditions (Figures 1-3). The bacterium completely metabolized the citrate released from uranyl-citrate complex, but not the EDTA released from the UEDTA complex. The UV-vis spectra of the culture medium during growth revealed the formation of a uranyl dicarbonate complex $\left[\mathrm{UO}_{2}\left(\mathrm{CO}_{3}\right)_{2}\right]^{2-}$ due to $\mathrm{CO}_{2}$ production from the metabolism of the carbon source. There was no change in the speciation of added uranyl carbonate. These results show that uranium phosphate is readily solubilized by bacterial action with formation of mobile to uranyl carbonate species. 


\section{Biotransformation under Anaerobic Conditions}

Biotransformation of uranyl nitrate and uranyl carbonate. A wide variety of facultative and strict anaerobic bacteria reduced U(VI) added as uranyl-nitrate or uranyl carbonate to U(IV) under anaerobic conditions. These include axenic cultures of iron-reducing, fermentative, and sulfate-reducing bacteria. Mixed cultures of bacteria in uranium contaminated ground waters and in wastes also reduced uranium.

Clostridia are strict anaerobic spore-forming fermentative bacteria ubiquitous in soils, sediments, and wastes. They catalyze the reduction of metals from higher to lower oxidation state. Reduction of soluble U(VI) to insoluble U(IV) by Clostridium $s p$. in culture medium was confirmed by X-ray absorption near edge spectroscopy (XANES) and X-ray photoelectron spectroscopy (XPS). Uranium was reduced only in the presence of growing or resting cells. Organic-acid metabolites, the extracellular components of the spent culture medium, and heat-killed cells failed to reduce uranium under anaerobic conditions (Francis et al 1994).

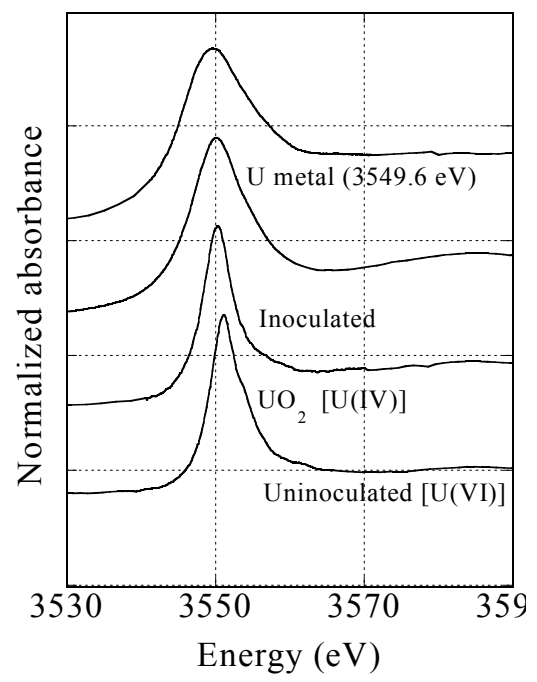

Fig. 4. Uranium reduction by Clostridium sp. XANES spectra of $U$ at the MV absorption edge shows the absorption edge for uninoculated $\mathrm{U}$ at $3551.1 \mathrm{eV}$, which is identical to U(VI) standard. The inoculated sample shows a peak at $3550.1 \mathrm{eV}$, which is lower than $\mathrm{U}(\mathrm{IV})$ but higher than $\mathrm{U}$ metal, indicating the presence of a highly reduced form of $U$, most probably a mixture of U(IV) and U(III).

Metabolism of uranyl-organic complexes by fermentative, iron- and sulfatereducing bacteria. Clostridium sphenoides (ATCC 19403), which utilizes

citric acid as the sole carbon source, metabolized equimolar Fe(III)-citrate with the degradation of citric acid and reduction of Fe(III) to Fe(II) but not the U(VI)citrate complex. However, in the presence of excess citric acid or added glucose U(VI)-citrate was reduced to U(IV)-citrate. Clostridium sp. (ATCC 53464) which ferments glucose but not citrate reduced Fe(III)-citrate and U(VI)-citrate only when supplied with glucose. The metals reduced by the Clostridium sp. were present in solution as metal-citrate complexes (Figure 5). These results show that the complexed uranium is readily accessible as an electron acceptor despite the inabil- 
ity of the bacterium to metabolize the organic ligand complexed to the actinide. We have shown that the metabolism of the metal-citrate complex is dependent upon the type of complex formed between the metal and citric acid. Fe(III) forms a bidentate complex with citric acid and was metabolized, whereas U forms a binuclear complex with citric acid and was recalcitrant (Francis et al 1992; Francis and Dodge,1993; Joshi-Tope and Francis 1995).

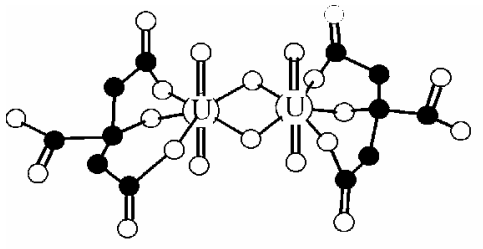

2:2 U(VI):citric acid

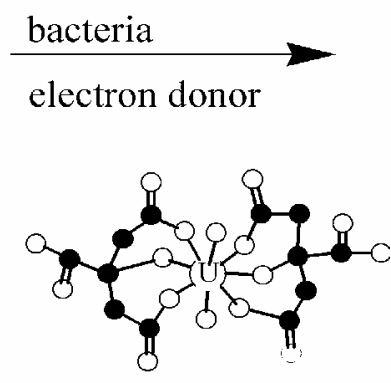

$1: 2 \mathrm{U}(\mathrm{IV})$ :citric acid

Fig. 5. Proposed mechanism of biotransformation of U(VI)-citrate to U(IV)-citrate by Clostridia.

The resting cells of the sulfate-reducing Desulfovibrio desulfuricans and the facultative iron-reducing Shewanella halotolerans bacteria reduced U(VI) complexed with oxalate or citrate to U(IV) under anaerobic conditions with little precipitation of uranium. The reduced U(IV) remained in solution complexed with oxalate or citrate (Ganesh et al 1997, 1999). These results show that complexed uranium is readily accessible for the microorganisms as an electron acceptor, despite the inability of the bacteria to metabolize the organic ligand complexed to the actinide.

\section{Acknowledgments}

This research was funded by the Natural and Accelerated Bioremediation Research (NABIR) Program, Office of Biological and Environmental Research (OBER) Office of Science, U. S. Department of Energy, under contract No. DEAC02-98CH10886

\section{Reference}

Dodge, C.J. and Francis, A.J. 1997. Environ. Sci. Technol. 31: 3062-3067.

Francis, A.J., C.J. Dodge, and J.B. Gillow. 1992. Nature 356:140-142. 
Francis, A.J. and C.J. Dodge. 1993. Appl. Environ. Microbiol. 59:109-113.

Francis, A.J., C.J. Dodge, F. Lu, G. Halada, and C.R. Clayton. 1994. 28:636-639.

Francis, A.J. 1998. J. Alloys and Compounds 271/273:78-84.

Francis A.J., C.J. Dodge, J.B. Gillow, and H.W. Papenguth. 2000. Environ. Sci. Technol. 34: 2311-2317.

Ganesh R., K.G. Robinson, G.R. Reed, and G. S. Saylor. 1997. Appl. Environ. Microbiol. 63:4385-4391.

Ganesh R., K.G. Robinson, L. Chu, D. Kucsmas, and G.R. Reed. 1999. Wat. Res. 33: $3447-$ 3458.

Joshi-Tope, G. and Francis, A. J. 1995. J. Bacteriol. 177:1989-1993.

Panak, P., S. Selenska-Pobell, S. Kutschke, G. Geipel, G. Bernhard, and H. Nitsche. 1999. Radiochim. Acta 84: 183-190.

Panak, P., J. Raff, S. Selenska-Pobell, G. Geipel, G. Bernhard, and H. Nitsche. 2000. Radiochim.Acta. 88: 71-77.

Sakaguchi, T. 1996. Bioaccumulation of Uranium. Kyushu University Press, Hukuoka, Japan. pp 61-95. 